\title{
4
}

\section{Inquiry, Critique, and Dissemination of Knowledge: Graduate Students Contributing to Wikipedia}

\author{
Nicola Simmons \\ Brock University
}

Graduate students use existing knowledge and are ultimately expected to add to that knowledge. Students in a Masters of Education entry course were asked to find a Wikipedia page related to the course topics, critique it, and make improvements to it to begin to develop these skills. In this paper, I examine ways in which their perspectives were transformed (Mezirow, 1991) regarding their roles in knowledge use and construction and how they grew as a result.

\section{Birth of the Wikipedia Assignment}

$\mathrm{M}$ ike Wesch's (2007a) video $A$ Vision of Students Today (over 4.8 million viewers) or his more recent (2007b) Web 2.0... The Machine is $U_{s} /$ ing $U_{s}$ (over 11.6 million viewers) are exemplars of how knowledge is socially constructed and how widely it can be shared. His keynote at the Society for Teaching and Learning in Higher Education's (STLHE) 2010 annual conference raised important questions about who creates and edits knowledge and caused me to think about how I might help graduate students develop their skills in knowledge investigation, critique, and dissemination.

Shortly after that event, I heard faculty at a workshop asserting their assignments were much stronger since they had stopped allowing students to use Wikipedia. I pondered this, wondering how disallowing a particular knowledge source helped students develop habits of scholarly inquiry. Soon after, at a graduate orientation came a reminder from our Department
Chair that, in graduate school, students were required to do more than use existing knowledge: they must create new knowledge.

This confluence of events caused me to think deeply about how we ask students to interact with knowledge and reflect on their role in that regard. As a result, I gave my students an assignment that required them to locate a course-related Wikipedia page and critique it, discuss its strengths and limitations, provide recommendations for improvement, and make the appropriate edits. The assignment was intended to help students develop their research skills in an introduction to graduate study course and also to prompt a discussion about the use of sources and crossreferencing.

In this paper, I outline the transformative learning (Mezirow, 1991) students experienced as a result of this assignment and discuss the paradigm shifts that can result when students engage in knowledge critique and diffusion. 


\section{Background Rationale}

Hammett and Collins (2002) note that graduate students expect to "see themselves as producers of knowledge and acknowledged members of an academic community" (p. 439). While students may be encouraged to publish or present their work, they may have little authentic opportunity to practice these graduate-level skills, particularly if they take a course-based route.

Wikipedia provides a platform that allows a student (at any stage) to engage in knowledge critique and publication. As Maehre (2009) outlines,

The students enter a turbulent environment where every syllable has to be defended by people with no authority over anyone else, where no editor has final say. This shows the student that the content of the work is paramount, not the author's credentials, however imperfect may be the process of shaping that content. (p. 235)

\section{Critical literacy skills}

While content is important, process skills such as critical thinking, problem solving, self-guided inquiry, and appropriate use of resources are essential in this century (Simmons, 2013) and are part of Ontario's expected graduate outcomes (McMaster University, 2010). Heil (2005), however, notes that students often take the route that yields the quickest information, foregoing academic journals and scholarly databases in favour of websites such as Wikipedia. O'Sullivan and Scott (2000) found students primarily chose internet resources for reasons of expediency, with only $10 \%$ noting limitations to information.

Post-secondary graduates must be critical of resources and technically savvy regarding online collaboration tools. We live with socially constructed knowledge, or "knowledge and information with multiple creators, collaborative knowledge created without traditional hierarchies of power, and through dispute and negotiation" (Maehre, 2009, p. 232). The $21^{\text {st }}$ century world calls for graduates who can collaborate easily with others in this regard. Critiquing and contributing to Wikipedia provides an opportunity for students to begin to develop these skills.

\section{Methods}

Students in two Fall 2011 sections of an entry course in graduate education were given the following assignment:

Contributing to Knowledge: Review a Wikipedia site (topic related to course) for strengths and potential areas for improvement, particularly regarding literature cited. Edit the site with your recommended changes. Accompanying paper approximately 4-6 pages (plus printed screen of site before your edits) cites several sources and makes strong connections to scholarly literature.

Ethics approval was granted to invite all students (38) to complete an online survey about their experiences with and reflections on the Wikipedia assignment. Nine students completed the survey comprised the following questions:

1. What benefits did you experience in completing the Wikipedia assignment?

2. What challenges did you experience?

3. What recommendations would you make for changing the assignment?

4. What do you recall as your key learning at the time of doing the assignment?

5. What did you learn through this assignment about the construction of knowledge?

6. In what ways, if any, have your perspectives shifted regarding use of Wikipedia and other resources for academic work?

7. As you now reflect back on the assignment, is there anything else you have learned?

8. Is there anything else you'd like us to know about your experiences with the Wikipedia assignment?

\section{Findings}

Overall, students' experiences of the Wikipedia assignment 
were extremely positive. For example, one said, "I have never been challenged in an assignment like that before," and another commented, "Fantastic experience. I would highly recommend it!" In this section, I first list challenges and then discuss what students learned about knowledge use and creation.

\section{Challenges}

The assignment was not without its challenges. Students noted,

Challenging to determine the depth to which to go in the assignment. Have the class sign up for topics so that you do not have multiple people in the same class editing one page. Provide some guidance on how to edit, code, and link on Wikipedia.

How much time and effort this assignment took. It was exhausting and after I had edited I was so excited to share my page with my family only to find out it was almost completely gone. It was a bit discouraging. This requires much more time and effort than any paper I have done in the past. Hours of reading, learning how to navigate the site, making changes, editing, and reflecting.

One student expressed frustration at website management issues, saying "some of the pages are locked and you have to be a member for a certain period of time. It was incredibly frustrating because I have very valuable information for that topic that I wanted to share and couldn't."

One student was cynical about who controls the site, adding, "I would be very wary of who is in charge of the site, why certain things stay and certain things change. I love the idea of the site in theory but I am a bit sceptical if it is really a free arena." In addition, the students noted the temporal character of online resources:

I learned that construction of knowledge using Wikipedia is too easy. Yet, it raises awareness and critical thinking about what is constructed on the Internet... most of the sources which the previous individual had used were all expired or non-existent at this point.

Thus, while students experienced technical challenges, these also contributed to their learning about online knowledge construction through Wikipedia.

\section{Perceived peer pressure}

While many noted technical challenges as reasons for not editing, some commented on their discomfort at changing others' posts:

I did not feel I had the authority or knowledge to put up what I had researched - I did not change any facts put up by previous editors; I felt I would be doing something wrong removing information put up by someone else.

One student reflected a sense of 'imposter syndrome' (Brookfield, 1995), regarding the ability to make a meaningful contribution:

I edited a page, and yes I did my best to research my topic as much as possible, but in the end I do not know if I was right. What if what I put down on that page is wrong? I may have aided in the deconstruction of knowledge.

\section{Wikipedia as a scholarly source}

While no comment was made by instructors on the veracity or reliability of Wikipedia as a resource, students quickly came to their own conclusions. One said, "For academic work, I generally use Wikipedia to get this overview and then go to more academic sources." Another noted, "To a certain extent it can be trusted but due diligence on the part of the student is a must to make sure information is correct" and another remarked, "I am much more cautious about what resources I use. I look at how academically strong my resources are."

\section{Meta-cognition about knowledge use and creation}

Students reflected on learning new skills of "critiquing 
sources of knowledge, learning to review and modify knowledge available online" and another discovered "the importance of accountability online and how I have valuable things to add to the body of knowledge and the construction of knowledge." One remarked, "knowledge changes and expands a lot faster than we think." Some comments were specific to Wikipedia:

I looked at how frequently certain pages were accessed, and how they've grown...the different security levels... the discussion board component of each page and all of the discussion (and arguments) that take place with regards to what should be on a certain page. I also learned about other projects Wikipedia is involved in, particularly in the higher education context.

One student's reflection described the assignment's impact on their thinking about Wikipedia as a resource that they could use, contribute to, and critique:

A rare opportunity to actually make a contribution to something. Made me really look at the language I was using and how I was writing...about what type of information I would want to read if I was looking at the page and to consider the reader when I was writing...Typically, students are told to stay away from Wikipedia because 'Joe Blow' can edit it and therefore the information isn't always reliable. However...I started looking into a lot of things Wikipedia does to increase the accuracy of the information that is posted, such as levels of security for pages that are frequently edited, as well as moderators that designate what needs to be done to pages to improve them. I think the assignment made me realize that Wikipedia isn't something that students should shy away from; it's something that, similar to everything else on the Internet, should be questioned.
Another said,

The power of social construction is incredible. Combining this assignment with the video by Mike Wesch resulted in me thinking about things in a different way... who determines what is knowledge? And what exactly is 'knowledge'...what is 'agreed' upon and published on the Wikipedia page is knowledge and people socially constructed this.

This critical questioning led to empowerment. Most commented on the assignment's impact on their developing identity as scholars. For example, one said, "I was able to become an 'author' of an 'article' on the internet," while another realized "I was able to contribute to the body of knowledge...to improve the information available to people on the internet." One said, "I felt like I was a part of something bigger than just an assignment - I was contributing to knowledge that could be around for many years to come," while another remarked that he or she "came to realize that creating knowledge was actually about constructing the self."

\section{Recommendations}

Most recommendations the students made pertained to technical issues; technical support would clearly be helpful. Another challenge was that two students chose the same website and struggled editing each others' work during the assignment period - but they also noted that this was a realistic challenge of Wikipedia edits. It is worth noting the students' growth in spite of these challenges:

I think that you've really tapped into an area that needs to be further explored because of how unique and relevant it is...how Wikipedia can be used for different assignments and try and get other instructors on board to try something new and help them do it. I think sometimes it's just easier to say 'do a paper' for $40 \%$ of your mark than come up with something innovative like this, so kudos for stepping outside of the box. 


\section{Final Thoughts}

If the role of graduate students is critiquing existing knowledge and transforming it, the more opportunities provided for doing that, the better. I agree with Maehre (2009) that "we are far too deep into a world dominated by dynamic social knowledge to deem it amateurish or somehow beneath the notice of our students" (p. 235).

Students outlined significant learning as a result of this assignment. Not only did they become knowledgeable about the particular topic they had chosen as they researched further details for their recommendations, they also experienced frame of reference shifts as they re-construed their perceptions of their role in knowledge creation (Kelly, 1955).

\section{Author's Note}

I am grateful to three anonymous reviewers whose advice has assisted in this preliminary article and in framing directions for Phase 2 of the research, now underway.

\section{References}

Brookfield, S.D. (1995). Becoming a critically reflective teacher. San Francisco, CA: Jossey-Bass.

Hammett, R. \& Collins, A. (2002). Knowledge construction and dissemination in graduate education. Canadian Journal of Education, 27(4), 439-453.

Heil, D. (2005). The internet and student research: Teaching critical evaluation skills. Teacher Librarian, 33(2), 26-29.

Kelly, G. (1955). The psychology of personal constructs: Volume 1, a theory of personality. New York: W.W. Norton.

Maehre, J. (2009). What it means to ban Wikipedia: An exploration of the pedagogical principles at stake. College Teaching, 57(4), 229-236.

McMaster University. (2010). Ontario's degree level expectations. Retrieved from http://cll.mcmaster. $\mathrm{ca} / \mathrm{COU} /$
Mezirow, J. (1991). Transformative dimensions of adult learning. San Francisco: Jossey-Bass.

O'Sullivan, M. \& Scott, T. (2000). Teaching Internet information literacy: Taking the first step toward technology education in the social studies. Educational Media and Technology Yearbook, 26, 115-124.

Simmons, N. (2013). Outcomes of learning: [Dis] engaging students in higher education. In $\mathrm{M}$. Kompf \& P.M. Denicolo (Eds.), Critical issues in higher education: The next generation. Rotterdam, The Netherlands: Sense Publishing.

Wesch, M. (2010). STLHE annual conference 2010: Opening plenary. Ryecast, Ryerson University. Retrieved from https://ryecast.ryerson.ca/21/ watch/597.aspx

Wesch, M. (2007a).Avision ofstudentstoday YouTube.http:// www.youtube.com/watch?v=dGCJ46vyR9o

Wesch, M.(2007b). Themachineisulingus. YouTube.http:// www. youtube.com/watch?v=6gmP $4 \mathrm{nk} 0 \mathrm{EOE}$

Wikipedia (2012). Wikipedia. http://en.wikipedia.org/ wiki/Wikipedia

\section{Biography}

Nicola Simmons teaches Masters of Education students in the Department of Graduate and Undergraduate studies in Education at Brock University, where she integrates and researches novel learning strategies. 